\title{
The Integration of Leprosy into the General Health Services*
}

\author{
S. G. BROWNE, OBE, MD, FRCP, FRCS, DTM
}

Twenty and more years ago, in my ignorance and enthusiasm, I would have considered the subject before us today to be without meaning or relevance, hypothetical rather than practical, raising an unnecessary question that permitted only the simplest of answers. For, with the eventual arrival of an effective treatment for leprosy, I was able, in the Belgian Congo, within a period of a few weeks to offer sulphones to over 5000 leprosy sufferers through a comprehensive rural medical service. The existing all-purpose health centres, supplemented by a network of dispensaries and manned by polycompetent medical auxiliaries, mediated the new treatment for leprosy, just as they had successfully tackled-or were still tackling-trypanosomiasis, yaws, tuberculosis, onchocerciasis, etc. Leprosy was not considered to be in any way unique or special: complete whole-population surveys had been made, every leprosy sufferer was known and documented, skin-smears and nasal smears had been obtained from all suspects; clinical notes had been kept up-to-date, and when treatment became available the existing facilities were utilized. There was no lengthy discussion of the "pros" and "cons" of integration and no awkward questions were raised by doctors, auxiliary health workers, patients or public. Integration just happened, and it happened smoothly and completely.

My next personal encounter with the subject was in the then Eastern Nigeria. Here, the leprosy service was the pioneer, the spearhead of all the health services in the rural areas. Thanks to the inspired vision and determination of a few percipient souls, a far-flung leprosy service had been inaugurated with the support and active co-operation of chiefs and people. Segregation villages had been established on communal initiative or with communal consent, and treatment instituted by sulphones distributed by monocompetent leprosy field workers. The need for general health services for the rural population was slowly appreciated. The leprosy service had proved its usefulness, and was fast becoming too top-heavy and over-organized for the much reduced patient load. What better foundation on which to build a rural health service than on the dwindling lep rosy service? Integration was being implemented, rural health centres established, and general medical facilities were being made available-when the disastrous civil war broke out, disrupting the service in process of integration and setting the medical clock back for a matter of decades.

Here, there are two personal experiences of integration: in one, leprosy was,

* Paper presented at the Congress of the All-India Association of Leprologists, Bhopal, October 1971. This paper was written to provoke thought and discussion on an important theme. The views expressed are the author's own and are not necessarily those of any organization with which he is associated. 
without ceremony or difficulty, grafted on to an existing all-purpose dispensary programme; in the other, leprosy was the stock on which the other health services were grafted. Given time, the result would have been similar if not identical. The process, the transition, was easier and more natural in the first example. The second is perhaps more applicable to the situation as we see it today in most parts of India.

\section{Why Integration?}

It behoves us, as workers whose prime interest is leprosy, to ask ourselves this searching and fundamental and far-reaching question. If we don't, we shall find that other people-government medical planners, sociologists, and ordinary tax-paying citizens and contributors to charities in India and elsewhere-are already asking the question, and attempting to find the answer.

The world is by no means standing still, and much has happened in recent years to make the integration of leprosy into the general health services of such a country as India more than a mere talking point-indeed, more like an item on the agenda. A programme that in years gone by may have been commendable and imperative and the only possible programme, may today (and even more tomorrow) be hopelessly antiquated and impractical. It may not even succeed in its primary purpose; and it may thwart the larger purposes of the public weal.

There are several reasons that make it imperative for us to consider this matter now.

\section{MEDICAL}

It has become trite to remark that leprosy is at long last entering the mainstream of medicine. Although that statement is by no means universally or completely true, it does reflect a changing attitude. Leprosy is now accepted in the research laboratory, the pharmacological assay department, and the immunological investigation unit. It is a fit and proper branch of medical study. Would that all medical schools gave sufficient time to, and emphasis on, leprosy in their curricula, clinical demonstrations, and examinations!

Now that the cause of leprosy is established and its relation to other mycobacterioses is being elucidated, there is no medical reason why leprosy should maintain its splendid isolation from the rest of medicine. Many hoary myths that have surrounded leprosy with mystery and mystique are disappearing more or less rapidly: its highly contagious nature, its incurability, its capriciousness. And many intriguing pathological conundrums are being logically explained in the light of recent research.

Again, effective leprosy treatment has been available long enough for its success to be patent to all but the wilfully blind. Now that the distinction between active leprosy infection and the late secondary sequelae of peripheral neuropathy is slowly becoming appreciated, leprosy as an infection is seen to have much in common with related mycobacterioses-though, to be sure, it seems to be uncommonly difficult to dislodge completely from its deep nidus in human tissues.

On grounds of infectivity, curability, absence of an intermediate host, leprosy does not require a separate service. From the standpoint of risk to public health, and the risk of serious, sudden and widespread epidemics, leprosy cannot demand special medical consideration, or special legislative measures. Any special pleading must be on socio-psychological grounds and not on medical grounds. 


\section{ECONOMIC}

The seriousness of the leprosy problem in any country is, roughly speaking, directly proportionate to the state of economic backwardness. In other words, leprosy poses the greatest problems in those lands which, by reason of low per capita income, are least able to devote sufficient funds to its control. This inescapable economic fact must colour our thinking and planning. Moreover, those countries face such inexorable and growing demands for defence, education, communications, industrial and agricultural expansion-quite apart from the health services in general-that a chronic, non-epidemic, non-killing disease like leprosy, expensively difficult to cure, would seem to require a disproportionate slice of the limited health budget.

Such countries also have more than their share of major health problems (malaria, tuberculosis, smallpox, schistosomiasis, to mention but a few), with the all-pervading spectre of undernutrition, if not actual starvation, never far away. If separate campaigns are to be waged against the killing diseases (like measles, whooping cough, tuberculosis and malaria), leprosy would not appear on any short list of priorities. It would, however, merit attention as a prime crippler and as a debilitating disease. But the deeper question remains: is it economically justifiable to attack health problems piecemeal, concentrating on separate disease entities concurrently or consecutively?

\section{OPERATIONAL}

The average villager in some areas is tired of being investigated and studied, parting with samples of blood and skin to successive survey teams who show little concern for him as a person, and provide nothing to rid him of his pressing ailments.

Furthermore, when a leprosy service is in operation, common humanitarian concern and good public relations alike demand that the leprosy sufferer-by no means exempt from the aches and pains to which mortal flesh is heir-should be able to obtain treatment for unrelated and intercurrent maladies. And so should his family, and his neighbours. Otherwise the charge will be levelled, and with justification, that we seem to be more concerned with a symptomless hypopigmented area of skin than with a distressing, painful and maybe fatal condition in the leprosy patient himself, or a member of his family, or in a fellow-villager.

It is quite impossible, on economic and financial grounds, to develop parallel services for the control of each of the major.endemic diseases, expensively duplicating organization and staff. The only way to deliver some sort of comprehensive medical care to the masses is through chains of all-purpose dispensaries, manned by polycompetent auxiliaries. It does not seem morally right to spend thousands of rupees on a single leprosy patient and do nothing for those who happen to be suffering from some other disease or disability. This disproportionate allocation of funds may have depended in the past on the special contributions of charitable organizations, but with increasing government direction of medical policy and progressive absorption of the activities of voluntary organizations, it is to be expected that the scope for unrestricted, unrestrained private initiative in this respect will in the future become much smaller.

The same predictive reasoning applies to rehabilitation. No country can afford a separate service for patients suffering from some deformity attributable to 
leprosy. While recognizing the invaluable pioneer work done in leprosy, acting oft-times as a stimulus or catalyst, we must admit that the disabilities that follow poliomyelitis, congenital deformities, infections and trauma together overshadow those produced by leprosy. Reconstructive surgery, physiotherapy, prostheses, vocational training, sheltered workshops, job placement, all should be organized for the total need, and not for leprosy victims alone.

\section{SOCIAL}

There are strong and convincing social arguments for the integration of leprosy into the general medical services, though it must be admitted that, in India at least, it is the objections and difficulties of a social nature that may appear to some to be insuperable. Stigma and prejudice, folklore and religious sanctions, ingrained attitudes and ignorance-all may be mobilized to prevent or impede any attempt at integration. But the very existence of a separate and distinct leprosy control programme, be it ever so successful, serves indirectly to reinforce and perpetuate the myth of the uniqueness of leprosy.

Far from being the neglected and utterly unprivileged outcast of society, the ex-leprosy patient in some communities is becoming an over-privileged and expensive non-productive citizen, making inordinate demands on the budget. And it is the crippled and mutilated, rather than the patients with early active disease, who succeed in capturing the sympathy and the money of many charitable organizations. The only way out of the present difficulties, and the prospect of a future impasse, is to advocate-on grounds of sheer economic necessity-the integration of leprosy into the general health services. With BCG vaccination against tuberculosis becoming more widespread, a further argument for integration becomes available.

The segregation of leprosy workers is, fortunately, becoming outmoded, but their special interests, and the time and effort the study of the subject demands, contain incipient germs of self-perpetuating mystique. We become a select society, a clique, almost a secret sect. In the past it was the individualist, the lone struggler, the non-conformist, of ten imbued with a burning desire to help the unfortunate victims of society's indifference and callousness, who did leprosy work. But now is the time for broader sympathies and wider knowledge, for catching a blinding glimpse of the obvious in human need that is not leprosy. In our legitimate concern for the leprosy sufferer, let us not forget the unpublicized and neglected victim of other infections and diseases.

\section{ADMINISTRATIVE}

With the abolition of discriminatory and coercive legislation concerning leprosy, and the demolition of the medical and economic reasons formerly advanced for keeping leprosy separate, there appears to be no administrative argument in favour of the continuation of the practice. Naturally, there will be vested interests of one kind and another, conservative of fice-holders unwilling and perhaps unable to change, empire-builders fearfully hanging on to their little crumbling domains. There will also be some paramedical workers with restricted outlook who are incapable of learning new skills and shouldering new responsibilities.

Geographically, too, the adaptation may not be without its administrative vicissitudes, as leprosy clinics become health centres, and monocompetent mobile teams assume more extensive rôles. However, taking the long view, there is 
everything to be gained from the new attitude, provided that at all levels the patients with leprosy are assured of a fair deal and a square deal at the hands of medical and administrative staff.

\section{THE TRANSFORMATION}

My task is almost done. I have demonstrated-at least to my own satisfaction-and have shown-at least from my own experience in the Congo and Nigeria-that leprosy should be, and can be, integrated into general health services. The outstanding formidable obstacles are mainly mental and social ${ }_{\jmath}$ and they are present in the minds of men-doctors and medical workers, political leaders, and ordinary people. Education is needed at all levels, and by all possible means and media. It is high time that attitudes changed.

Of course, there will always be a need for those with special knowledge of leprosy, and special skills in diagnosis, treatment, reconstructive surgery, research. These desiderata must be integrated into the endemic disease control departments of the health ministries, available at referral centres, and become part and parcel of the professional equipment of doctors and paramedical workers according to the need. The artificial separation of leprosy will cease, and leprosy will be no more a distinct medical and administrative entity than tuberculosis or trachoma. The social aspects of leprosy will receive their rightful emphasis and financial subvention-no more and no less.

The transformation of treatment centres, and the in-service training of the specialized leprosy paramedical workers to enable them to assume the role of polycompetent medical auxiliaries (or basic health workers) will pose many problems, none of them insuperable, though many at first sight appear forbidding and insoluble.

The voluntary agencies hitherto concerned exclusively with leprosy will need to appreciate wider areas of human need. In a way, one of their principal aims will have been attained: leprosy is accorded its rightful place in the thinking and action of the health service, and because of this, leprosy will be well on the way to control. There will, however, still be a place for the voluntary agencies, to initiate, to supplement and to stimulate; to infuse a spirit of disinterested and devoted service into the treatment of that slightly contagious mycobacterial disease that we still call "leprosy". 